\title{
Logistics Processes Management in Supply Chain
}

\author{
Dr. Paweł Ślaski \\ Professor Assistant \\ Military University Of Technology \\ Department of Logistics, Institute of Logistics
}

\begin{abstract}
The aim of the article was to develop a model for managing logistics processes in the supply chain. The use of process analysis and integration of logistics processes in the supply chain enabled the continuity of power in the process of supply and in the production process and it also enables the effective and efficient distribution process management. Basing on the developed map of logistics processes author of the article described the place in the process where one can apply optimization methods of quantity and quality. By using statistical quality control it was possible to shorten the duration of the adoption process of delivery to the warehouse, thereby lowering the cost of quality control. Integration of supply processes and production logistics in the supply chain enabled the continuity of power of parts in the production process, however thanks to the combination of methods DRP (Distribution Requirements Planning), Kanban, VMI (Vendor Managed Inventory) and CPFR (Collaborative Planning, Forecasting and Replenishment) we obtain the effective and efficient distribution process management.
\end{abstract}

Keywords: Integration of logistics processes, statistical process control, process map

THE RESEARCH PROBLEM WAS PUT IN THE FORM OF A QUESTION:

How basing on the modern methods of logistics processes management to effectively manage the integrated supply chain?

Research methods used in this article:

1. Process analysis,

2. Mapping of processes,

3. Techniques: VMI (Vendor Managed Inventory), CPFR (Collaborative Planning, Forecasting and Replenishment), Kanban, DRP (Distribution Requirements Planning),

4. Statistical Quality Control.

\section{INTRODUCTION}

Supply chain management is a skillful combination of processes of supply, production and distribution of market needs and the way how to properly adapt to accelerating changes of these particular needs. The objectives of supply chain management, such as: minimizing costs, improving the quality of goods and services, increase of flexibility, diversity and the reaction time can be achieved by treating the chain as a whole, which consists of various processes and activities related to each other. The process approach leads to the conclusion that the objectives set for each process are the only components of the main objectives of the supply chain, rather than the existing goals for each other. "Integrated school" takes supply chain management as a paradigm, according to which the supply chain is not only a set of functional 
blocks or organization that intersect flow of products and information, but divides these blocks horizontal to the single processes, which are then subject to optimization measures (Bechtel, Jayaram, 1997 ).

Improving supply chains should go in the direction of integration of key logistics processes from end users via the initial suppliers who provide products, services and information and add value for customers and other stakeholders of the chain. The starting point in improving the chain, striving to increase its efficiency and competitiveness should be a thorough analysis of customer needs, and the goal - optimization of four basic indicators: quality, cost, completion date and risk. This approach to improving the supply chain have a considerable impact not only on the general improvement but also on the growth of integration and coordination processes, and thus will improve the operation between cooperating downstream (JacynaGołda, 2015).

Process management in modern supply chains is a response to the growing turbulence environment and individualization of customer needs and expectations. It involves optimizing the structure of the business components, by seeking to maximize participation in this structure elements which add value and minimize the share of inefficient operations.

The search for organizational structures of the new generation should take into account the conditions in which they carry out their mission, and their design should hover around the identified processes, the effects of which the customer will verify and accept (Grajewski, 2007).

\section{CONSTRUCTION OF THE INTEGRATED MODEL OF SUPPLY CHAIN}

The aim of the integrated supply chain model is consistent presentation and description of the main tasks of the chain linked in a sequential and logical way. A model of logistic processes is a description of a reality chain seen from a functional and dynamic point of view.

The developed model was based on the following assumptions:

1. Each link in the supply chain is considered from the point of view of basic processes.

2. Sequential system processes in the supply chain (input of the succeeding process is simultaneously the output of the proceeding one).

3. The use of modern information technology and appropriate methods and tools to synchronize the streams of supply and demand.

Analyzed logistic processes in the supply chain, ie. Supply, production and distribution are presented in a value chain, which is also the first stage of integration.

Fig. 1. Presents the 1 st phase of the model of the integrated supply chain.

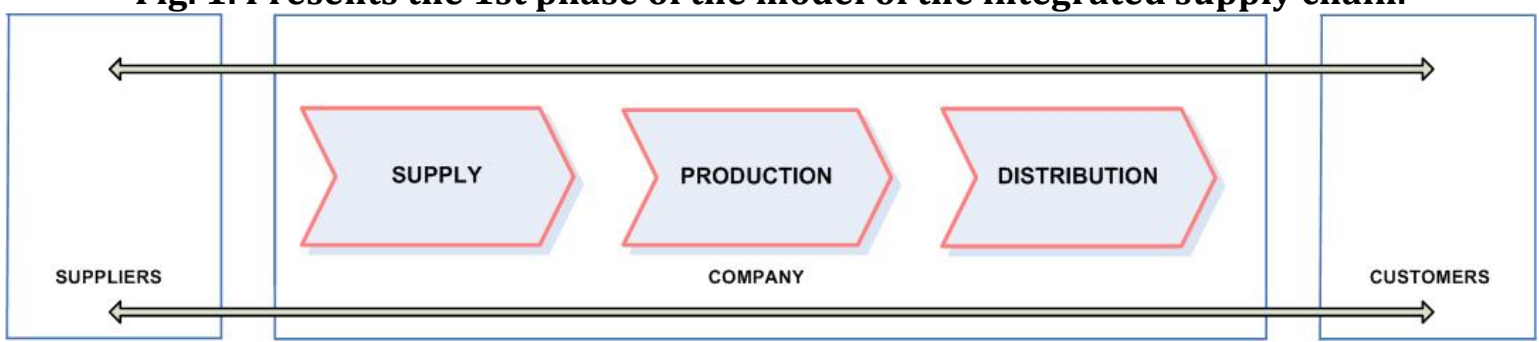

Fig. 1. The first phase of the integrated model of supply chain

Source: Bechtel Ch., J. Jayaram (1997), Supply Chain Management: A Strategic Perspective, The International Journal of Logistics Management, Vol. 8 Iss 1. 
The second phase (basic) of the model are the maps of logistic processes: supply, production and distribution. Process maps are the basis on the way to their improvement and they are a graphic portrayal of the main value-added activities, linked in a sequential manner and logically implemented in a specific order. They also represent a temporal interpretation of specific activities involved in the flow of goods, services and information in the supply chain.

The first detailed map of the applicable procurement process. This process can be divided into nine basic actions which add value in a direct way.

\section{Activity 1. Identification of needs}

This effect was related to the determination result of the process, an output parameter. The need (the product) may be demand for the product, service or information that the customer accepts. The needs are reported to the department sourcing company based on a purchase order with a detailed specification of goods or services or methods of re-ordering.

The most commonly used method of re-ordering is based on:

1. Simulation methods, eg. Monte Carlo method,

2. Scenario analyzes associated with minimum cost inventory at optimum parameters ordering, eg. The size of supply and minimum levels of the administred stock.

3. Deterministic and stochastic methods based on the economic size of the delivery of information, the size of the safety stock and periodic inspection,

4. Methods of group procurement of goods,

5. Methods of ordering with limited capital and in terms of discontinuity demand.

\section{Activity 2. Description}

At this stage there is a detailed description of the product, which is a source of information for potential suppliers. There are several ways to describe a product or service, and they all must accurately convey information providers to the needs of customers. The basic methods of description of the product or service may include:

1. Description by genre or standard (standard products and services, supply chain partners aware of the needs of the market),

2. Description by brand (products and services from one preferred supplier),

3. Description by specification (required detailed description of the product or service, eg. the process of production, control systems, physical dimensions),

4. Description by the result (eg. technical support in the operation of the device).

\section{Activity 3. Identification and assessment of suppliers}

In this operation the organization defines the evaluation criteria of the identified potential external suppliers. These can be, eg. The ability of designing products, the level of management, the condition of the company, planning and cost structure, the opportunity to establish long-term cooperation, planning and control systems, etc.

\section{Activity 4. Supplier selection}

Completion of the identification and evaluation is another activity associated with the final choice of supplier. This selection can be made from a list of preferred providers or organizing a tender or conducting negotiations.

\section{Activity 5. Preparation of contract}

This action is related to the preparation of the document, which authorizes the supplier to deliver the product. It sets out the conditions, ie. The price, date and place of delivery and quality requirements. Very often at this stage the EDI technology is used (Ang. Electronic Data 
Interchange). Basing on the Internet, the actual needs of customers go to the suppliers, often bypassing the intermediate links. The turnaround time is also shortened, it minimizes the volume of stocks and thus reduces logistics costs.

\section{Activity 6. Control of accomplishment}

This activity is related to the determination of the order status at each stage of the project.

\section{Activity 7. Receiving and control}

This activity includes the adoption of the product in accordance with the specifications of the contract and its verification quantitative and qualitative. You can use statistical methods of collection and quality control of goods. The use of statistical quality control by assessing alternative using small samples is described later in this article.

\section{Activity 8. Approval of invoices and payment}

After the receiving of the product the company usually makes electronic funds transfer to the bank account provider.

\section{Activity 9. Data update}

The process can be repeated, so after the completion of the orders there is the update of the database concerning the cooperation with the suppliers (Bozarth, Handfield, 2007, p. 392400).

Basing on such specific activities the map of the procurement process developed using the diagram EPC (Extended Event Driven Process Chain) of ARIS architecture was created (Architecture of Integrated Information Systems). The main objects in this diagram are functions, events and logical operators that connect to each other in a logical sequence as a fundamental course of the process (Figure 2) (Aris 6, 2003).
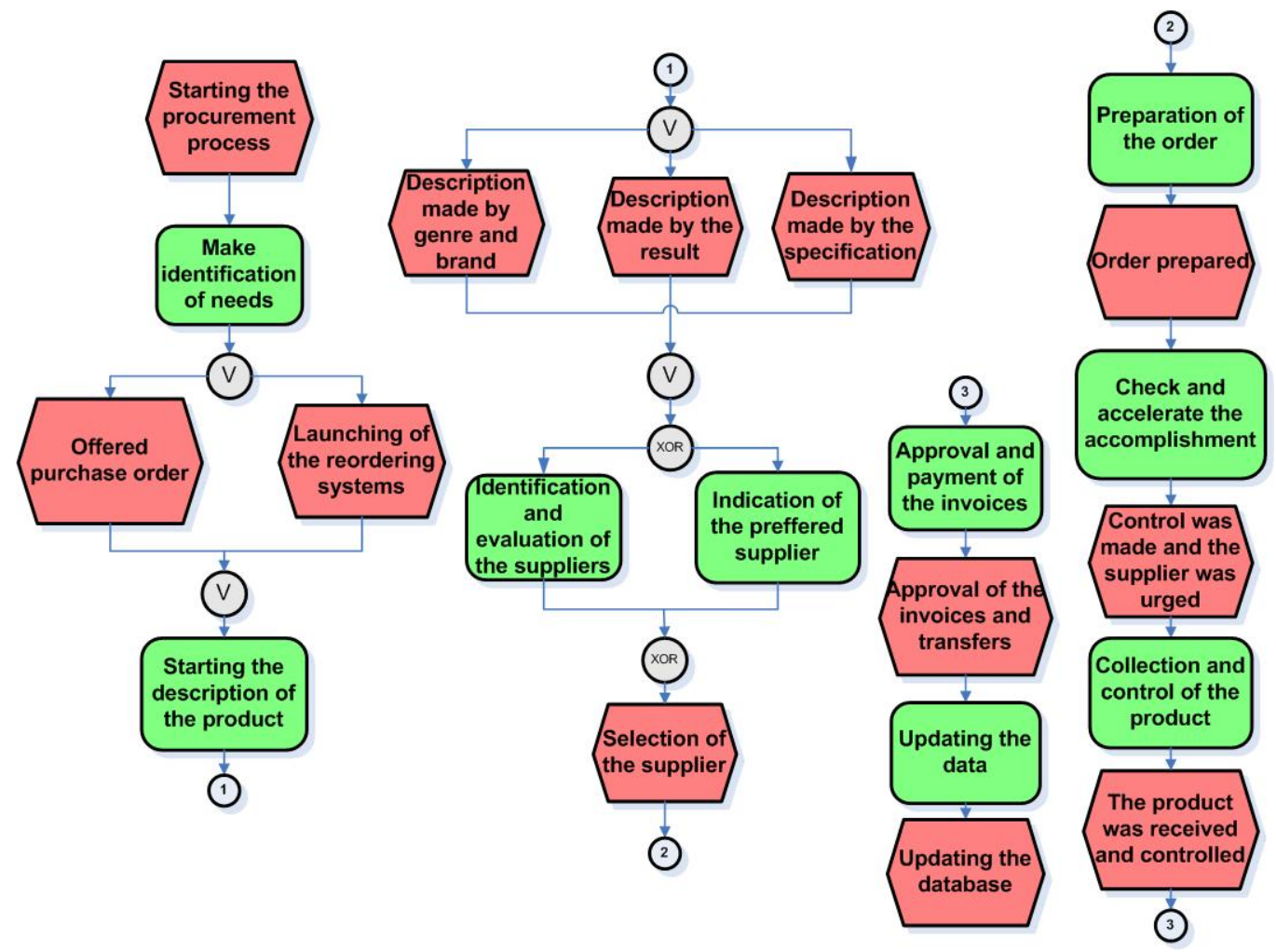

Fig. 2. Map of the procurement process Source: Own. Based on (ARIS 6, 2003). 
According to the author, to make the management of the integrated supply chain effective and efficient it is advisable to use creative solutions (innovative) adding value to the process. Therefore, when analyzing the procurement process the author suggested the use of statistical quality control during the inspection and testing supplies. It was assumed that between the supplier and the recipient the plan of the quality reception of large batches was made. Disqualifying defectiveness $w 1=0,05$, permissible defectiveness $w 2=0,01$ were determined, and risk: of the recipient $\alpha 1=0,05$ acceptance of the defective batches and of the supplier $\alpha=$ 0.05 the rejection of the proper batches. These values mean the reception of the batch of allowable defectiveness $1 \%$ and $5 \%$ risk of rejection of the party providers of good and rejection of batches of disqualifying defectiveness equal to $5 \%$ and $5 \%$ of the risk of the recipient's acceptance of the defective batch. Delivery of goods numbering tens of thousands of stocks may be received and subjected to quality control based on a small sample that represents the entire batch.

A good way to determine the study plan $\mathrm{m} / / \mathrm{n}$ that is determining the size of a random sample of $\mathrm{n}$ and the acceptable number of bad pieces of a sample $\mathrm{m}$ is the solution of equations (Dziubiński, 1980; Szkoda, 2003):

$$
\begin{aligned}
& \mathrm{P}\left(\mathrm{D} / m, n ; w_{1}\right)=\mathrm{P}\left(\mathrm{Z} \leq m ; n, w_{1}\right)=\sum_{k=0}^{m}\left(\begin{array}{l}
n \\
k
\end{array}\right) w_{1}^{k}\left(1-w_{1}\right)^{n-k}=\alpha_{1} \\
& \mathrm{P}\left(\mathrm{D} / m, n ; w_{2}\right)=\mathrm{P}\left(\mathrm{Z} \leq m ; n, w_{2}\right)=\sum_{k=0}^{m}\left(\begin{array}{l}
n \\
k
\end{array}\right) w_{2}^{k}\left(1-w_{2}\right)^{n-k}=\alpha_{2}
\end{aligned}
$$

These equations can be solved using an approximation to the binomial distribution by the Poisson distribution using the approximate formulas:

$$
\begin{aligned}
& \sum_{k=0}^{m} \frac{\lambda_{2}^{k} e^{-\lambda_{2}}}{k !}=\alpha_{2} \\
& \sum_{k=0}^{m} \frac{\lambda_{1}^{k} e^{-\lambda_{1}}}{k !}=\alpha_{1}
\end{aligned}
$$

Where: $\lambda 1=$ nw $1, \lambda 2=$ nw2

For adopted $\alpha 1$ and $\alpha 2$, the parameters $\lambda 1$ and $\lambda 2$ and determined between the supplier and the recipient of the defectiveness $\mathrm{w} 1$ and $\mathrm{w} 2$ determine the $\mathrm{n}$ sample count. After determining the sample count, the decision to accept or reject the batch can be taken even before examining all the pieces. The study collected randomly one by one, and based on her research and previous, it takes a decision to accept, reject or examine the need for another art (Kahn, 1996). The decision regarding the acceptance or rejection of batches of goods shall be taken depending on the location, in which will be the curve of the study. Graph (Figure 3) shows the essence of the sequential research. 


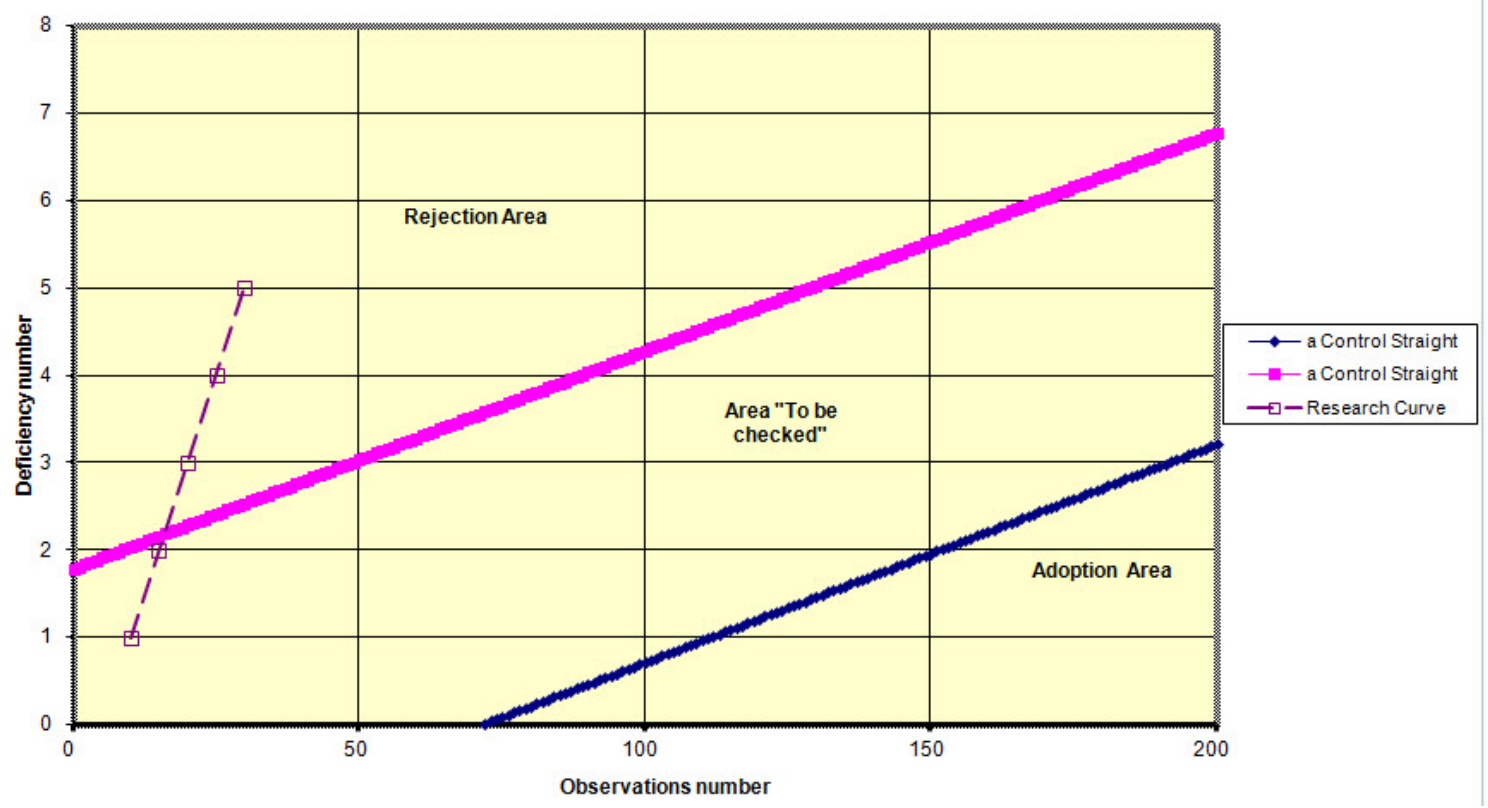

Fig. 3. Testing sequential goods

Source: Own. Based on (Firkowicz, 1970).

The study shows that the use of statistical quality control (SKJ) to manage supply process allows you to measure its effectiveness and efficiency and shortens the time for a large delivery to the warehouse, thus reducing the cost of the reception quality of goods.

Another process is connected with production logistics. The basis of this process is to determine the size of the independent demand in different periods and placing it in the production schedule. The size of this demand "forces" the need to determine the structure of the product, that is, the amount of components and components included in its composition. To properly identify the needs the essential information on stocks and planned supply is also needed. For a more complete analysis, the author of the article suggested combining this process with operational control kanban. Such integration in the planning process of production logistics enables continuity of supply components and materials on the production lines and the accumulation of optimal volume of stocks of materials used in the assembly process. Figure 4 shows a detailed map of the planning process of production logistics of using the combined methods of material requirements planning (MRP) and operational control kanban. 

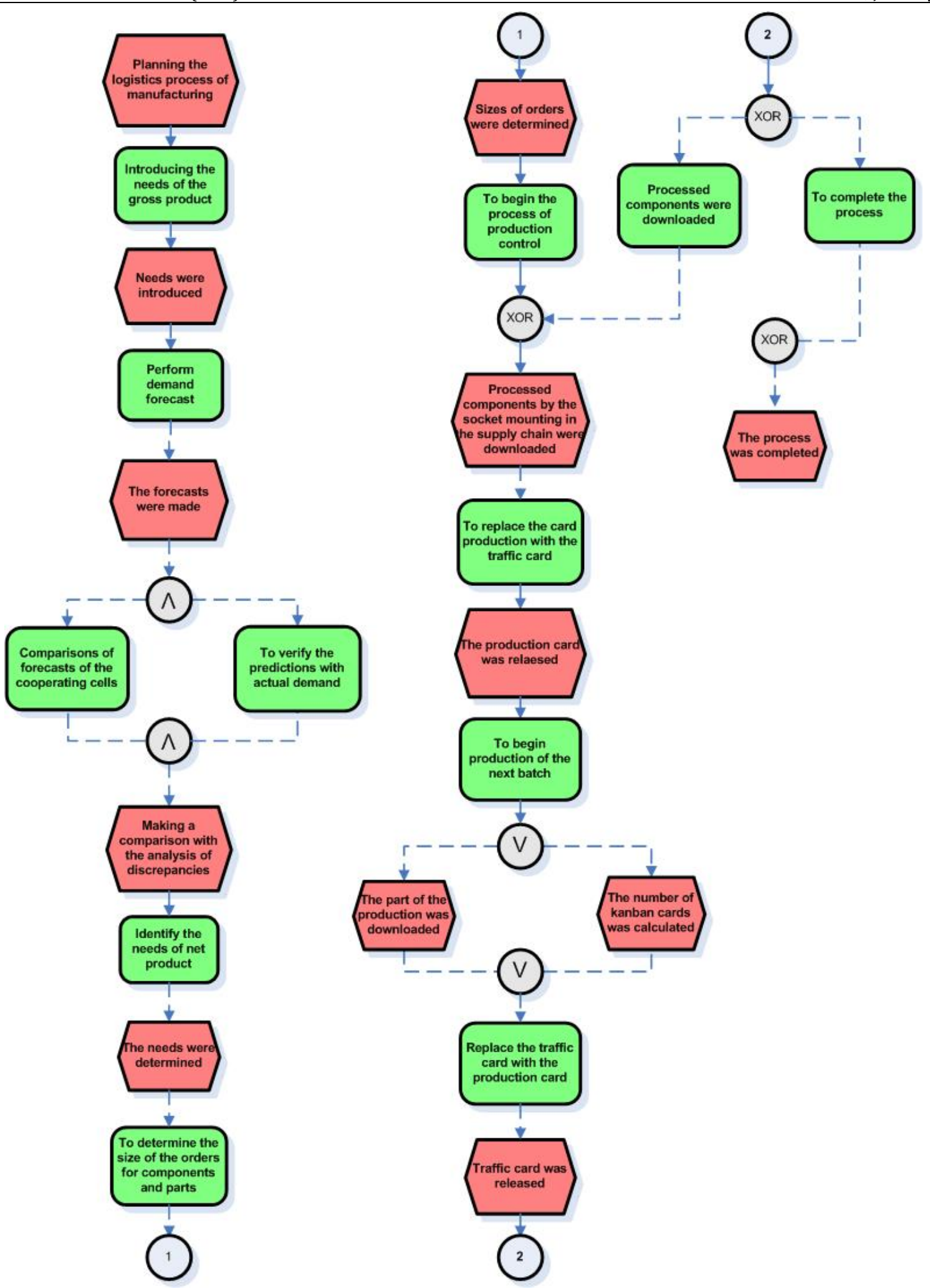

Fig. 4. Map of the planning process of production logistics Source: Own. Based on (ARIS 6, 2003).

The last process is the distribution process. It was presented in the value chain as the optimal schedule for delivery of ordered goods. In the unified communication system of the customer with the provider, knowing the forecast of demand, you can plan the efficient distribution schedules in advance and keep them correct constantly, when there are delays in deliveries. It includes three phases: 
1. Developing demand forecasts from customers and send them to the supplier along with other parameters of the procurement process (the states of stocks, the size of orders, replenishment cycle times, etc.).

2. Collecting data transmitted from the client at the provider's level and developing an initial delivery schedule;

3. Balancing the performance and developing the optimal delivery schedule.

Figure 5 shows the process map for planning the optimal delivery schedule

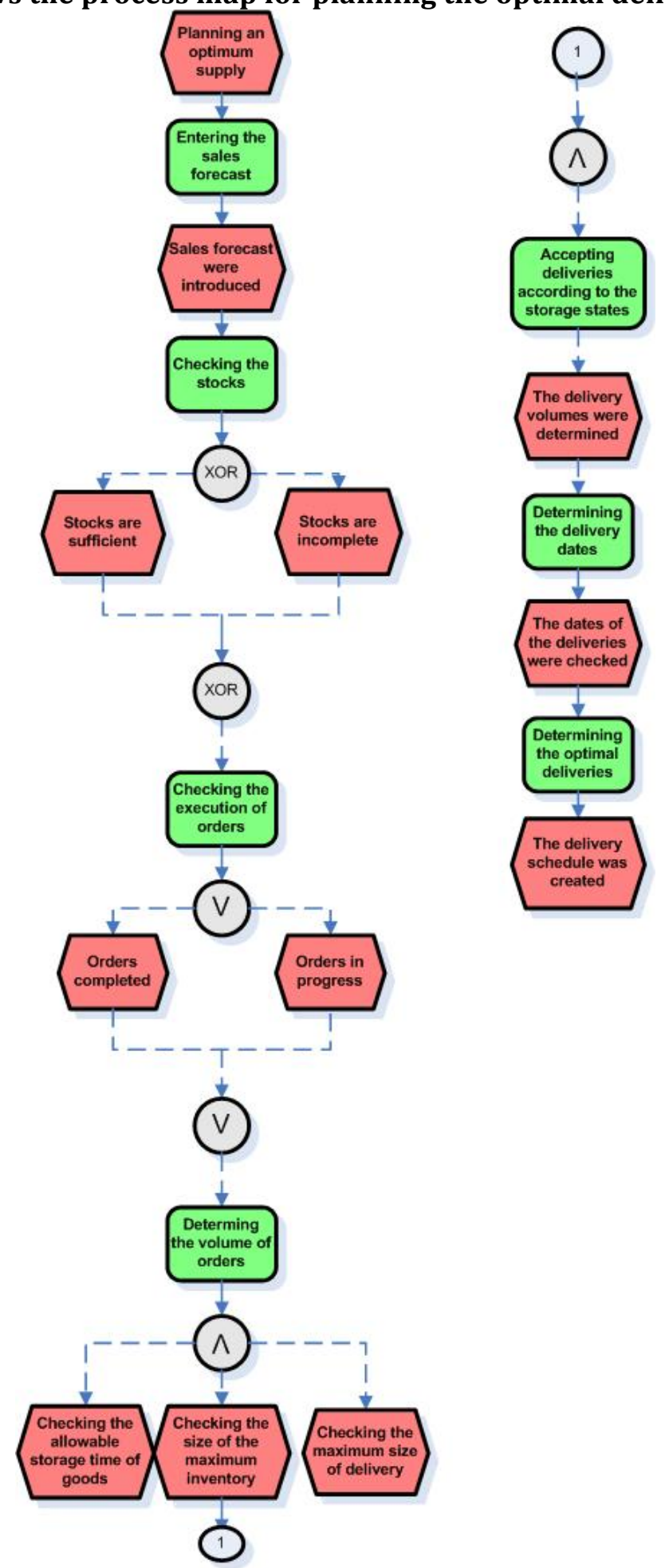

Fig. 5. Map of the planning of optimal supply

Source: Own calculations based on (ARIS 6, 2003). 
Integration and joint production and sales planning in the supply chain were possible thanks to the use of VMI (Vendor Managed Inventory), CPFR (Collaborative Planning, Forecasting and Replenishment) techniques and EDI (Electronic Date Interface) messages sent over the Internet.

Thanks to VMI it was possible to increase the efficiency of the flow of goods, services and information in the supply chain as a result of customer's inventory management by the supplier. The supplier is responsible for the recipient's stocks. Using EDI messages, they receive from the client data over the Internet related to: sales volume and production, states inventory and needs of completion them. Basing on the received information the supplier can create the optimal delivery schedules for both parties, because the amount and type of products ordered are not generated by the consumer, but created on the basis of their needs by the supplier.

The main objective of CPFR technique was to increase the efficiency of supply chains by optimizing inventory up and down the chain, while maintaining the standards of customer service. CPFR compares the forecasts of the cooperating companies, automatically capturing significant differences in these sizes, which are made available by cooperating analysis teams and analyzes the differences that exceed the agreed standards. This tool, eg. in the form of Excel, lets also basing on graphical analysis of charts, verify the actual data with the corresponding forecasts. This enables the cooperating companies to flexibly react and take appropriate corrective action to the situation (Fig. 6) (Ślaski, 2012).

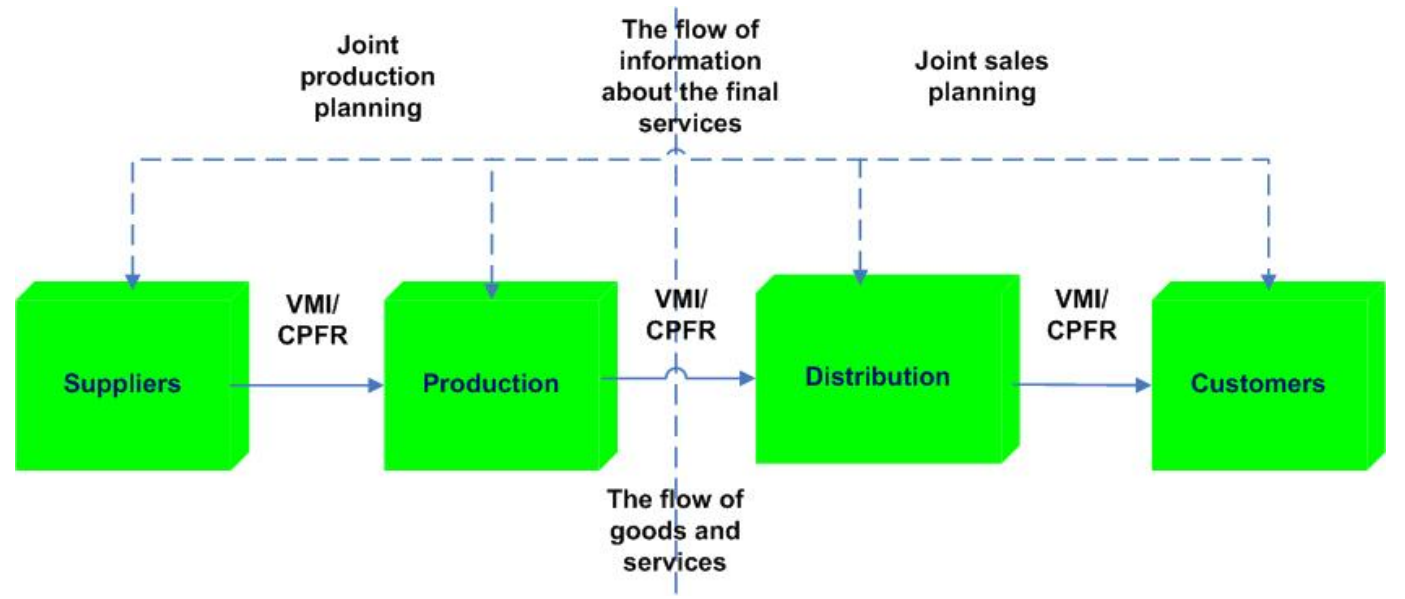

Fig. 6. Links co-operation in the supply chain using techniques CPFR and VMI Source: own, based on J. Witkowski, Zarządzanie łańcuchem dostaw, koncepcje, procedury, doświadczenia, PWE, Warszawa 2003.

\section{CONCLUSIONS}

Considering the operating conditions of modern supply chains, it seems that the process approach is the natural determinant of achieving an increase in their efficiency, though it gives them an opportunity of building more dynamic solutions than the ones, flexibly responding to environmental signals. Therefore, the search for organizational forms, supporting and discounting the effect of processes in supply chain management is a challenge for contemporary theorists, managers, designers and logistics processes.

Enterprises that have made the description of all the processes and methods of improving them should then introduce the concept of process management, link maps developed from existing information technology and create an integrated supply chain. 
In this article the author proposed some innovative solutions. Basing on the developed core processes maps author defined actions in processes where you can apply optimization methods of quantity and quality.

As a result, it was possible to shorten the duration of the adoption process of delivery to the warehouse, thereby lowering the cost of quality control. Integration processes in the supply chain enabled the continuity of power supply parts in the manufacturing process and effective and efficient management of the distribution process.

\section{Literature}

1. Aris 6, Easy Design, Podręcznik użytkownika, (2003), Poznań: IDS Scheer,

2. Bechtel Ch., Jayaram J. (1997), Supply Chain Management: A Strategic Perspective, The International Journal of Logistics Management, Vol. 8 Iss 1 pp. 15 - 34,

3. Bozarth C., Handfield R. (2007), Wprowadzenie do zarządzania operacjami i łańcuchem dostaw, Gliwice: Helion,

4. Dziubiński I., Świątkowski T. (1980), Poradnik matematyczny, Warszawa, PWN,

5. Firkowicz Sz. (1970), Statystyczne badanie wyrobów, Warszawa: Wydawnictwa Naukowo-Techniczne,

6. Grajewski P. (2007), Organizacja procesowa, Warszawa: PWE,

7. Jacyna-Gołda I. (2015), Decision-Making Model for Supporting Supply Chain Efficiency Evaluation, Warszawa: The Archives of Transport, Volume 33, Issue 1,

8. Kahn M, G, MD, PhD, Thomas C. Bailey, MD, Sherry A. Steib, Victoria J. Fraser, MD, William Claiborne Dunagan, MD (1996), Statistical Process Control Methods for Expert System Performance Monitoring, USA: Journal of the American Medical Informatics Association Volume 3 Number 4,

9. Szkoda J. (2003), Diagnozowanie jakości partii wyrobów metodą statystycznej kontroli odbiorczej z oceną alternatywną, Warszawa: Diagnostyka'28, Polskie Towarzystwo Diagnostyki Technicznej,

10. Ślaski P. (2012), Model efektywnej obsługi klienta, Warszawa, Systemy logistyczne wojsk, nr 38. 